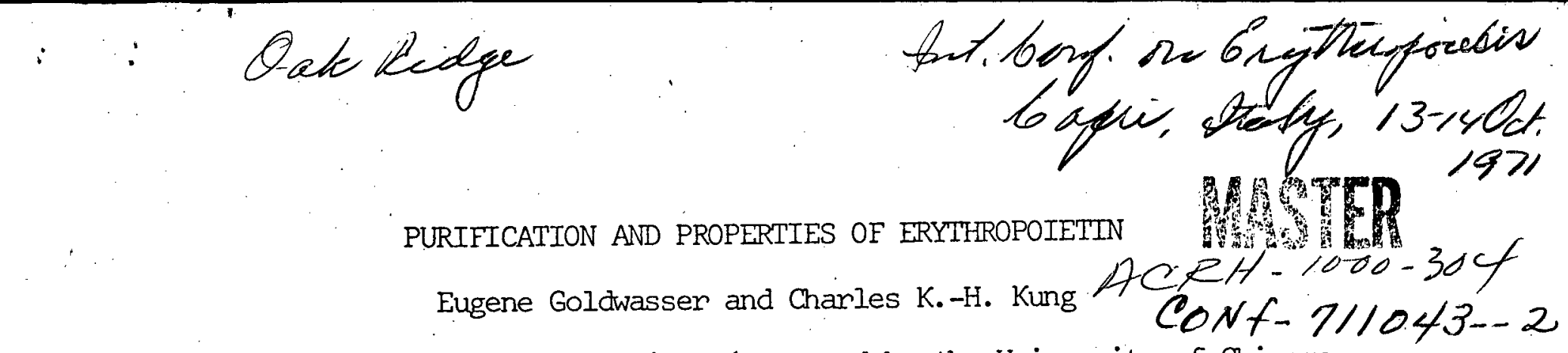

Argonne Cancer Research Hospital (operated by the University of Chicago

for the United States Atomic Energy Conmission), and Department of

Biochemistry, University of Chicago

Chicago, Illinois 60637 U.S.A.

The need for pure erythropoietin, in order to study, more completely, its chemistry, mode of action, and therapeutic role has been evident for sone time. We present, here, a summary of the methods used to purify sheep plasma erythropoietin ( 1 ), evidence for its state of purity, and some of its chemical properties. Although erythropoietin can now be prepared in pure form, the methods need improvement so that the yield may be increased. Substantially larger amounts than have yet been prepared will be required for structure determination and identification of the chemical features responsible for its unique role in the regulation of red blood cell formation.

\title{
Purification of Erythropoietin
}

Sheep, made anemic by injection of phenylhydrazine, were bled when their hematocrits were at a suitably low levei (2). A summary of the steps in purification is as follows: (details of the first five stages have been published [3]).

(1) The plasma was dialized at $\mathrm{pH} 4.5$ against five volumes of water;

(2) Batch adsorption was carried out on DEAE cellulose and followed by elution at high salt concentration (Step I);

(3) Step I was dialyzed, then run through IRC-50 at $\mathrm{pH} 6$ and the effluent was collected. (Step II neither accumulated nor characterized.) 


\section{DISCLAIMER}

This report was prepared as an account of work sponsored by an agency of the United States Government. Neither the United States Government nor any agency Thereof, nor any of their employees, makes any warranty, express or implied, or assumes any legal liability or responsibility for the accuracy, completeness, or usefulness of any information, apparatus, product, or process disclosed, or represents that its use would not infringe privately owned rights. Reference herein to any specific commercial product, process, or service by trade name, trademark, manufacturer, or otherwise does not necessarily constitute or imply its endorsement, recommendation, or favoring by the United States Government or any agency thereof. The views and opinions of authors expressed herein do not necessarily state or reflect those of the United States Government or any agency thereof. 


\section{DISCLAIMER}

Portions of this document may be illegible in electronic image products. Images are produced from the best available original document. 
(4) Step. II had its $\mathrm{pH}$ lowered to 5.0 before adsorption on IRC-50; it was then eluted at $\mathrm{pH}$ 6, dialyzed, and lyophilized (Step III).

(5) A solution of Step III was precipitated with ammonium sulfate between 0.53 saturated at $\mathrm{pH} 6.3$ and. 0.67 saturated at $\mathrm{pH} 3.3$, dialyzed, and lyophilized (Step IV):

(6) Step IV was dissolved in $3 \mathrm{M} \mathrm{LiCl}$ and precipitated with alcohol, and the fraction precipitating between $65 \%$ and $90 \%$ was collected (P7).

(7) The P7 fraction had the salt removed by membrane ultrafiltration and was chromatographed on sulfoethyl Sephadex. The active fractions were eluted with $0.015 \mathrm{M}$ acetate at $\mathrm{pH} 5.0,0.0175 \mathrm{M}$ at $\mathrm{pH} 5.28$ and 0.020M at $\mathrm{pH}$ 5.6. (These were pooled.) (SE).

(8) The desalted SE fraction was put on a column of hydroxylapatite at very low ionic strength (4) and eluted with $10^{-3}$ M phosphate at $\mathrm{pH} 7.4(\mathrm{HT})$.

(9) The HT fraction was chromatographed on methylated-albumin Kieselguhr (5). The fraction eluted with 0.01M phosphate $\mathrm{pH} 7.2$ was collected (MAK-7).

The MAK-7 fraction was assayed in vivo by both the fasted rat method (6) and the polycythemic mouse method (7). Both assays agreed. The protein concentrations of the later fractions were determined by measurements at $194 \mathrm{~nm}$ (4). For the cruder fractions, protein concentrations were determined at $278 \mathrm{~nm}$. Table I shows the specific activities (i.u./mg of protein), yields, and purification factors through the fractionation.

Assay of the MAK-7 fraction in vitro, by the marrow cell culture method (8) showed that the log dose-log response curves were parallel and 
linear from 0.004 i.u. to about 0.20 i.u. with respect to both hemoglobin synthesis and iron uptake. There was a definite flattening of the curve at $0.40 \mathrm{i} . u$. but no evidence of decreased hemoglobin synthesis, as was seen in the past with less pure fractions (Fig. 1).

The overall yield was very low, but in view of the many steps involved in purification and the extremely minute amounts present, even in plasma from severely anemic sheep, this was not surprising. The final purification factor was in excess of 1 million.

Purity of Erythropoietin

Testing for heterogeneity was done by gel electrophoresis. When other fractions of very high potency were examined by polyacrylamide gel electrophoresis on a micro scale, we found that staining with Coomassie blue (9) yielded very much less intense bands than was expected from staining the same amount of serum albumin. A fraction with potency of $6500 \mathrm{i} . \mathrm{u} . \mathrm{mg}$ protein and labeled with 125I (10) was run on a similar gel, the gel was sliced and the slices were fixed and washed before counting. Almost all the radioactivity was lost from the slices. This was true regardless of the fixative used, and we concluded that erythropoietin and its glycoprotein contaminants were not precipitated by the usual protein precipitants. For this reason, we did not examine the MAK-7 fraction by staining the gel after electrophoresis; instead, we labeled the erythropoietin fraction with ${ }^{125}$ I before running it on the gel, and evaluated the gel by slicing it into $0.9 \mathrm{~mm}$ slices before counting.

The upper frame in Figure 2 shows the results of a run at $\mathrm{pH} 8.6$. There is an asymmetric majon peak with a relative mobility of 0.52 . The shoulder on the slower side amounts to about $7.5 \%$ of the total area under the peak. It 
is evident that there is considerable loss of radioactivity in the slices after fixation in sulfosalicylic acid and washing (closed circles). When the labeled MAK-7 fraction was desialated using a protease-free sialidase from Cholera vibrio before running on the gel, the asymmetry was removed. The middle frame of Figure 2 shows that after desialation there was a single symmetrical peak with a relative mobility of 0.35 . The figure also shows that after desialation, erythropoietin becomes precipitable with sulfosalicylic acid (closed circles).

The finding that some glycoproteins do not appear as stained bands in conventional gel electrophoresis makes it evident that the usual criterion of purity using precipitated, stained bands on the gel, is not adequate. Substantial contamination with glycoprotein, soluble under the conditions used, may be present. but undetected.

The bottom frame of Figure 2 shows the results of assay in vitro of erythropoietin recovered by eluting slices of the polyacrylamide gel after electrophoresis. For this experiment we used a less pure fraction (120 i.u./mg of protein). The major peak of biological activity had a relative mobility of 0.54 ; there was also a trace of activity where desialated erythropoietin would have been.

These data indicate that at $\mathrm{pH} 8.6$ there is a major component with erythropoietin activity and that the main contaminant is erythropoietin that has been desialated, either in vivo or, more probably, during the isolation procedure. This is also true when electrophoresis is carried out at pH 6.0. Since desialated erythropoietin is without activity in both in vivo assays we can calculate that the true potency of the pure erythropoietin is $8900 \mathrm{i} . \mathrm{u} . / \mathrm{mg}$ of protein. 
Properties of Purified Erythropoietin

Because of the very small amounts of pure erythropoietin available, the chemical properties we report here must be considered preliminary and tentative. Sheep plasma erythropoietin (MAK-7) is composed of $74 \%$ protein and $26 \%$ carbohydrate. The carbohydrate consists of $10 \%$ sialic acid (16 residues/mole), 6\% galactose (18 residues/mole), 4\% mannose (12 residues/mole), $4 \%$ glucosanine ( 12 residues/mole) and $2 \%$ glucose ( 6 residues/mole). Micro determination of the amino acid composition. is not yet satisfactory, but within the limit of detection there appears to be no methionine or cysteine and only small amounts of arginine, tyrosine and valine. The absorbance maximum in the middle ultraviolet range is $276 \mathrm{~nm}$ and the $1 \%$ absorbancy at that wavelength is 7.4 .

The apparent molecular weight of the iodinated erythropoietin determined by electrophoresis in gels containing sodium dodecyl sulfate (II) is 37000 . Since there is an appreciable anionic charge due to the sialic acid residues, results by this method may be erroneously low. The desialated MAK-7 fraction had a molecular weight of 41000 by the same method. When corrected for the sialic acid content the molecular weight of the "native" erythropoietin was calculated to be 46000 . Only a single peak of label was found on the gel, indicating that erythropoietin consists of a single chain, or, possibly, of chains held together by covalent bonds other than disulfide bonds.

Independent information about molecular size can be obtained by the study of erythropoietin activity of fractions derived by gel-filtration and sucrose gradient sedimentation. The results reported by Lukowsky and Painter (12) and by Olesen and Fogh (13) cannot be interpreted unequivocally since the calculation of molecular weight from Stoke's radii obtained by gel 
filtration measurements alone, assumes that the molecule studied is spherical. If there were any asymmetry, the apparent molecular weight would be higher than the true value.' Both studies cited suggest that the apparent molecular weight of erythropoietin is about 60000, using an assumed partial specific volume. O'Sullivan et al. (14) have combined measurements of sedimentation velocity in a sucrose gradient with gel filtration (15) to avoid the ambiguity due to possible asymmetry, and report molecular weight and sedimentation coefficient of 32000 and $2.6 \mathrm{~S}$ (using an assumed partial specific volume of 0.70 ).

Our own first estimate of sedimentation coefficient by measurement of biological activity of a Step IV preparation in fractions from a sucrose gradient yielded a value of 5 to $6 \mathrm{~S}$. A similar experiment with ${ }^{125}$ I-labeled MAK-7 showed two peaks; the major one, about two-thirds of the total, had a sedimentation coefficient of $4.6 \mathrm{~S}$, and the minor one had a sedimentation coefficient of about 2S. Determination of $S$ by another method measuring biological activity, the Yphantis-Waugh separation cell method in the analytical ultracentrifuge (16), yielded a value of 4.4S. Since there is evidence of damage during the iodination procedure we suggest that the sucrose gradient component with the smaller $S$ value was derived from the original biologically active component with an $S$ value of 4.6 .

The calculated frictional ratio using a molecular weight of 46000 and sedimentation coefficient of 4.65 is 1.12 . If the molecule were an unsolvated prolate ellipsoid the axial ratio would be 3 . If the data of O'Sullivan et al. are used, the frictional ratio is 1.58 and the axial ratio is 10 . We have no explanation for the differences found for both the molecular weight and sedimentation coefficient. 
The effects of chemical and enzymic probes, of known specificities, on the biological activity of erythropoietin can give us some information about the chemical nature of the hormone (Table 2). The requirement for tyrosine or histidine was deduced from the inactivation by fluoroscein isothiocyanate (17) and by iodination; that of arginine or lysine from the inactivation by trypsin. Treatment of erythropoietin with hydroxynitrobenzylbromide, which is specific for tryptophan, also caused loss of activity (18). Reaction with p-chloromercuribenzoate, on the other hand, did not.inactivate, nor did esterification of primary alcohol groups with anhydrous formic acid (19).

The placing of sialic acid in both the "required" and "not required" columns needs explanation. We have found that removal of the terminal sialic acids by either acid or sialidase treatment causes complete loss of activity whether the in vivo assay is done in fasted rats or plethoric mice. When the assay was done in vitro, no loss of activity could be detected. Our speculations about this seeming paradox suggested that the erythropoietin molecule itself contained the sialic acid that was required for stability in vivo but not for action on the tanget cells of the marrow (20). The work of Ashwell and his collaborators makes it clear that this is the case generally for glycoproteins (21), and that removal of the penultimate galactose or its oxidation can restore the clearance rate of the asialoagalactosyl glycoprotein to a near normal value (22). The same may be true of exythropoietin activity; we are now testing the biological activity of desialated erythropoietin that has had any terminal galactose modified.

A more complete chemical characterization of erythropoietin will have to wait until more material becomes available for study. So will testing of its clinical efficacy. When one considers that in plasma from very anemic 
animals (containing 1 i.u. per $\mathrm{ml}$ ) erythropoietin represents between $0.0001 \%$ and $0.0002 \%$ of the protein, the task of isolation, in pure form, of milligram quantities: can be seen as a formidable one.

One altemative source of erythropoietin is the urine of severely anemic patients. Espada (23) has published data showing that a high degree of purification from this source is possible, and if enough raw material were available, pure human erythropoietin might be produced in large quantity. Work on this is now going on in several laboratories. Erythropoietin might also be derived from kidney cell cultures. Some evidence $(24,25)$ has been published suggesting that this is feasible but, to date, no large scale preparation has been described.

It is clear that much more chemical information reganding the structure of erythropoietin and the relationship between stmacture and function is needed. Once the basic chemistry is understood, it may be possible to synthesize erythropoietin, making it available for clinical use and a wide variety of fascinating experiments on red blood cell differentiation. 
References.

1. Goldwasser, E. and Kung, C. K.-H. Proc. Nat. Acad. Sci. (U.S.) ' 68, 697 (1971).

2. White, W. F., Gurney, C. W., Goldwasser, E. and Jacobson, L. 0. Recent Prog. Hormone Res. '16, 219 (1960).

3. Goldwasser, E., White, W. F. and Taylor, K. B. Biochim. Biophys. Acta 64, 487 (1967).

4. Goldwasser, E. and Kung, C. K.-H. Ann. N. Y. Acad. Sci. 149, 49 (1968).

5. Mandell, J. D. and Hershey, A. D. Anal. Biochem. 1, 66 (1960).

6. Fried, W., Plzak, L. F., Jacobson, L. O. and Goldwasser, E. Proc. Soc. Exp. Biol. Med. 94, 237 (1957).

7. Cotes, P. M. and Bangham, D. R. Nature 191, 1065 (1961).

8. Krantz, S. B., Gallien-Lartigue, O. and Goldwasser, E. J. Biol. Chem. 238, 4085 (1963).

9. Dunker, A. K. and Ruckert, R. R. J. Biol. Chem. 244, 5074 (1969).

10. McConahey, P. J. and Dixon; F. J. Int. Arch. Allergy Appl. Inmunol. 29,185 (1966).

11. Weber, K. and Osborn, M. J. Biol. Chem. 244, 4406 (1969).

12. Lukowsky, W. and Painter, R. H. Canad. J. Biochem. 46, 731 (1968).

13. Olesen, H. and Fogh, J. Scand. J. Hemat. ' 211 (1968).

14. O'Sullivan, M. B., Chiba, Y., Gleich, G. J. and Linman, J. W. J. Lab. Clin. Med. 75, 771 (1970).

15. Siegel, L. M. and Monty, K. J. Biochim. Biophys. Acta 112, 346 (1966).

16. Yphantis, D. A. and Waugh, D. F. J. Phys. Chem. 60, 623 (1956).

17. Lowy, P. H. and Borsook, H., in Erythropoiesis (L. O. Jacobson and M. Doyle, Eds.), Grune \& Stratton, New York, 1962, p. 33. 
18. Lowy, P. H. and Keighly, G. Biochim. Biophys. Acta I60, 413 (1968).

19. Lowy, P. H., Keighly, G. and Borsook, H. Nature 185, 102 (1960).

20. Goldwasser, E., in Current Topics in Developmental Biology (A. A. Moscona and A. Monroy, Eds.), Vol. I, Academic Press, New York, 1966, p. 173.

21. Morell, A. G., Gregoriadis, G., Scheinberg, I. H., Hickman, J. and Ashwell, G. J. Biol. Chem. 246, 1461 (1971).

22. Morell, A. G., Irwine, R. A.' Stemlieb, I., Scheinberg, I. H. and Ashwell, G. J. Biol. Chem. 243, 155 (1968).

23. Espada, J. and Gutnisky, A. Acta Physiol. Latinoam. 20, 122 (1970).

24. Ozawa, S. Keio J. Med. 16, 193 (1967).

25. McDonald, T. P., Martin, D. H., Simmons, M. L. and Lange, R. D. Life Sci. 8, 949 (1969). 
TABLE 1

Purification of Sheep Plasma Erythropoietin

\begin{tabular}{lccc}
\hline Fraction & I.U./mg. Protein & Yield & Purification Factor \\
\hline Anemic plasma & 0.007 & $100 \%$ & -112 \\
Step I & 0.8 & 64 & 430 \\
Step III & 3.0 & 35 & 3,700 \\
Step IV & 26 & 17 & 35,700 \\
P7 & 250 & 13 & 81,300 \\
SE & 570 & 3 & 285,000 \\
HT & 2000 & 1 & $1,180,000$ \\
MAK-7 & 8250 & $\ldots .3$ & $\ldots$ \\
\hline
\end{tabular}


TABLE 2

Chemical Requirements for Activity of Sheep Plasma Erythropoietin

\begin{tabular}{lc}
\hline \multicolumn{1}{c}{ Required for Activity } & Not Required for Activity \\
\hline Tyrosine and/or histidine & Cysteine \\
Arginine and/or lysine & Threonine and/or serine \\
Tryptophan & Sialic acid \\
Sialic acid & S \\
\hline
\end{tabular}




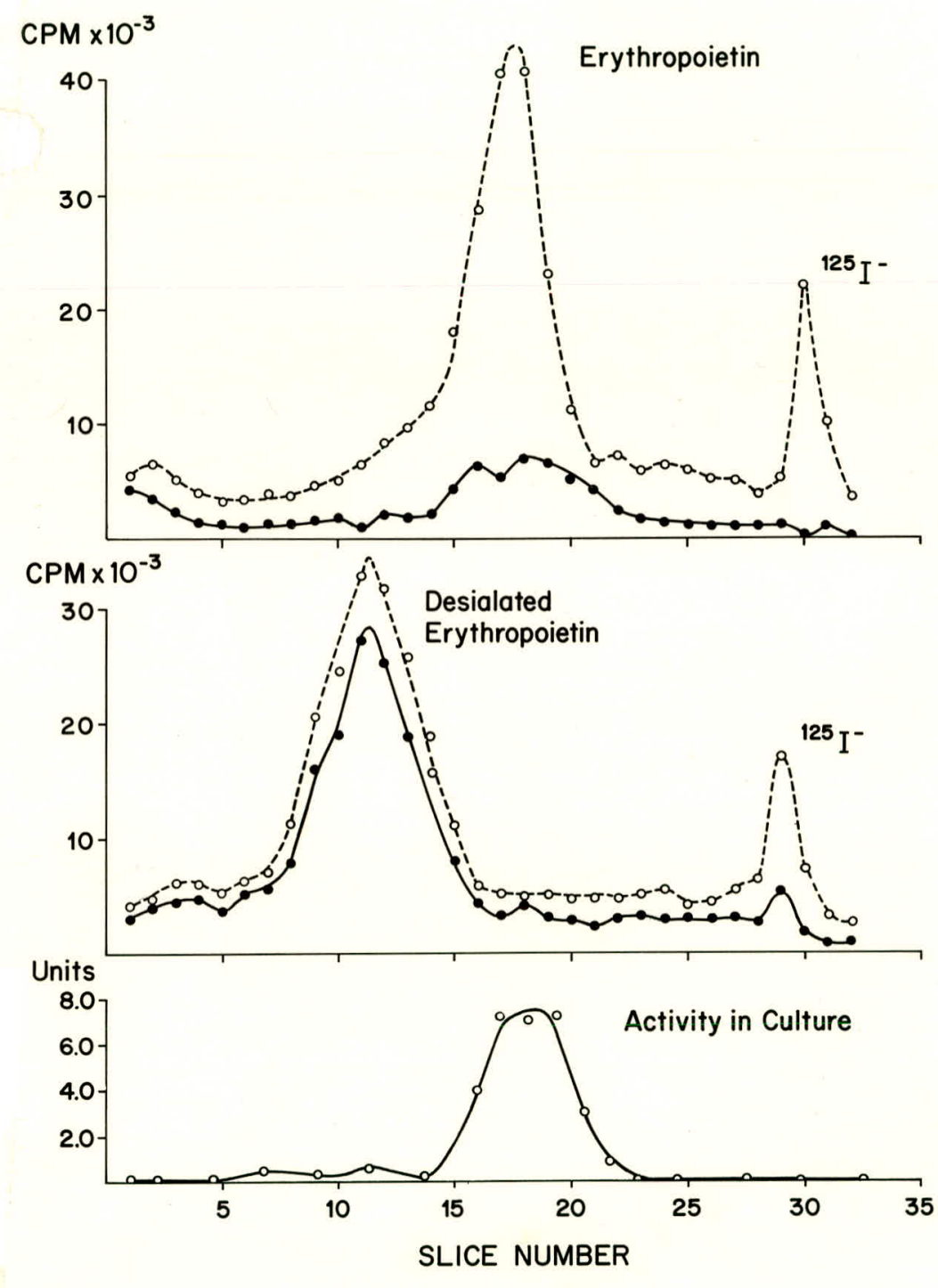


CPM

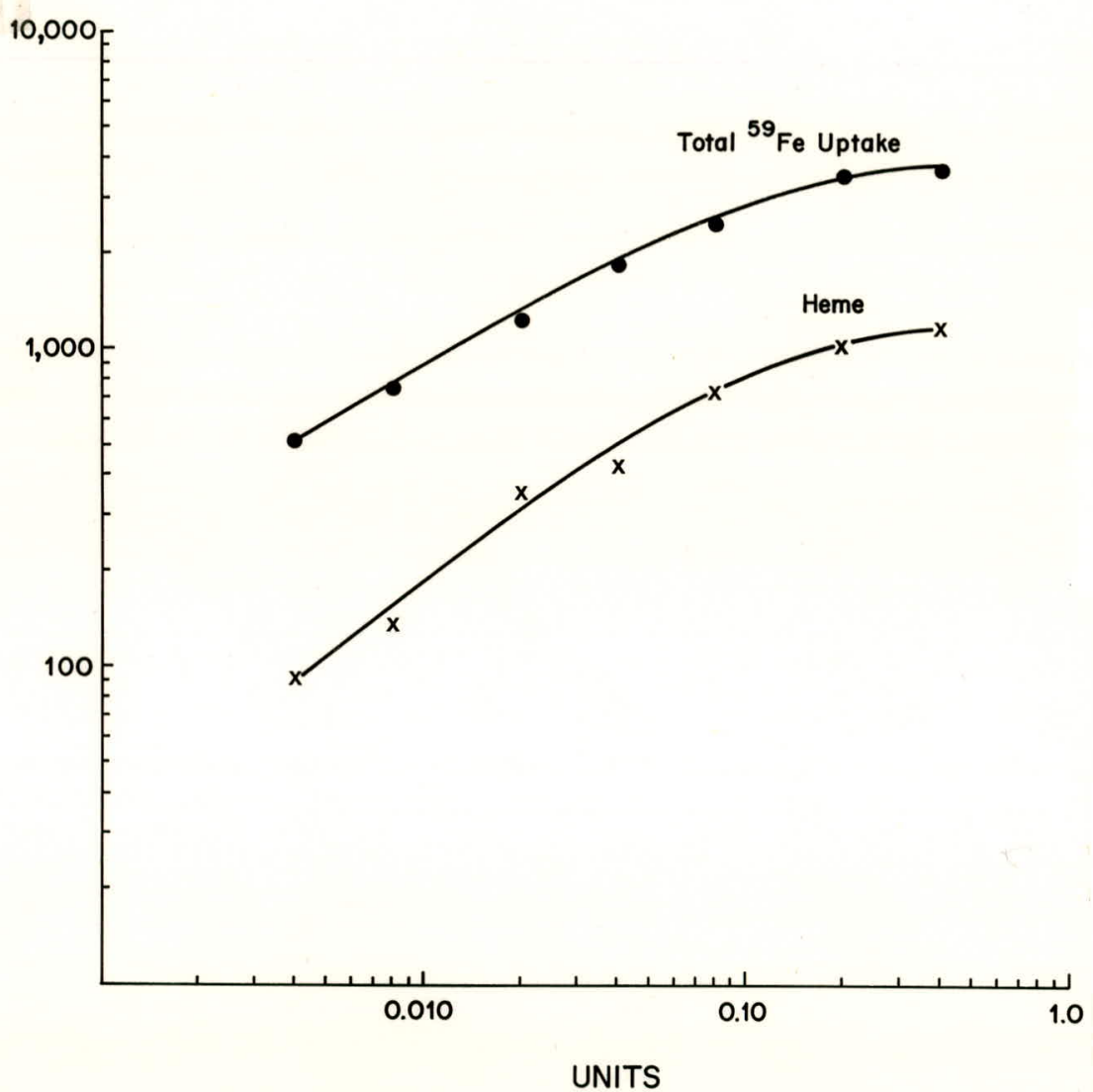

UNITS 